\title{
Pesquisa histórica das estatísticas: temas e fontes ${ }^{*}$ Historical study of statistics: topics and sources
}

\section{Nelson Senra}

Professor da Escola Nacional de Ciências Estatísticas / Instituto Brasileiro de Geografia e Estatística Rua São Salvador, 41, apto.704 22231-130 Rio de Janeiro RJ - Brasil

nelson.senra@ibge.gov.br
SENRA, Nelson. Pesquisa histórica das estatísticas: temas e fontes. História, Ciências, Saúde - Manguinhos, Rio de Janeiro, v.15, n.2, p.411-425, abr.-jun. 2008.

\section{Resumo}

Tomando as estatísticas como objeto de estudo (e não como meio de análise) e fazendo-o a partir de uma dimensão histórica no quadro teórico de uma sociologia das estatísticas, propõem-se temas e indicamse fontes para possíveis pesquisas históricas. Os temas e as fontes aqui sugeridos desdobram a abordagem realizada na coleção História das Estatísticas Brasileiras: 1822-2002 (em quatro volumes), que vem sendo editada pelo Instituto Brasileiro de Geografia e Estatística. Trata-se, em última instância, de se fazer uma história do Brasil pelo prisma do querer e do fazer as estatísticas, ou, dito de outra forma, do se governar utilizando-as.

Palavras-chave: informação estatística; sociologia das estatísticas; história das estatísticas; história política e social; história das instituições.

\section{Abstract}

By taking statistics as an object of study (rather than a means of analysis) and taking a historical perspective from within the theoretical framework of the sociology of statistics, topics and sources are put forward for possible historical research. The topics and sources suggested here are a development of the approach adopted in the four-volume collection História das Estatísticas Brasileiras: 1822-2002 brought out by the Instituto Brasileiro de Geografia e Estatística. Ultimately, the aim is to write a history of Brazil from the perspective of the purpose and practice of statistics, or in other words, their use in the practice of government.

Keywords: statistical information; sociology of statistics; history of statistics; political and social history; history of institutions. 
$\mathrm{E}$ ste texto tem por objetivo estimular a pesquisa histórica das estatísticas (vale dizer, da informação estatística, da atividade estatística, das instituições estatísticas, dos sistemas estatísticos etc.), indicando temas e fontes. Há vários temas a serem estudados, por nunca terem sido vistos ou por não terem sido vistos de modo completo e/ou suficiente. Alguns ensejariam artigos; outros permitiriam sustentar dissertações e teses. Faremos sugestões de temas a partir dos quatro volumes da coleção História das Estatísticas Brasileiras: 1822-2002 que idealizamos e realizamos como pesquisador do Centro de Documentação e Disseminação de Informações (CDDI), do Instituto Brasileiro de Geografia e Estatística (IBGE). ${ }^{1}$

Antes de passar aos temas e às fontes, contudo, convém oferecer algumas noções (em linhas gerais, por certo) de uma sociologia das estatísticas - campo de pesquisa em definição, com uma comunidade de pesquisadores ainda pequena e sem unidade -, ao qual nosso estudo histórico se filia, ao menos em termos de escolha temática. Nesse campo de pesquisa, as estatísticas são vistas como objeto de estudo e não como meio de análise, o que é mais comum. Como meio de análise das realidades, as estatísticas, ao desenharem espaços sociais, servem à geração das políticas públicas, às ações de setores privados e aos pesquisadores acadêmicos. Como objeto de estudo, investiga-se um processo produtivo que nasce numa demanda ex ante (demanda fundadora) e finda numa demanda ex post, havendo entre esses extremos o tempo da oferta, nas etapas de produção e de disseminação. ${ }^{2}$

As estatísticas permitem que mundos distantes e ausentes se façam próximos e presentes e, por isso mesmo, configuram uma tecnologia de distância; uma vez conhecidos, os mundos tornam-se pensáveis e governáveis, donde as estatísticas configuram uma tecnologia de governo.

As informações estatísticas são expressões coletivas, embora sejam sempre fundadas em informações individuais que, por sucessivos processos de agregação, as constituem. As informações estatísticas, por sua natureza, ordenam as múltiplas e disformes individualidades, que são desconhecidas e ingovernáveis; partem delas, sempre, mas as superam, reconfigurandoas em individualizações (individualidades individualizadas). Ou seja, cada um se vê através do outro: ora nos vemos tendo renda maior, ou menor, que a renda média, ora nos vemos tendo mais, ou menos, anos de escola que a média, ou que a grande maioria da população, e assim em diante. Fazemos isso sem nos darmos conta.

Figurados esses coletivos sociais, os governos podem agir, formulando políticas públicas, políticas de ação direta ou de simples sugestão à ação de outros agentes. Sim, as estatísticas trazem às mesas dos decisores públicos ou privados, em tabelas, gráficos e cartogramas, uma população - em si e em suas relações sociais e econômicas existentes num território. Desse modo, elas são uma forma de saber e uma fonte de poder; são uma forma muito especial de informação, que porta a força 'neutra' dos números. Por eles, não é preciso estar na coisa para sabê-la - noções como grande e pequeno, bonito e feio, quente e frio, e outras, sempre polêmicas, ganham limpidez determinada.

Expressas em números, as estatísticas valem-se da linguagem que se quer, na tradição científica do Ocidente, objetiva e universal. Como números são signos, eles se organizam sintaticamente. Mas, como sempre nas ciências, são números construídos, revelando realidades previamente idealizadas, nunca ao acaso dos gostos, dos caprichos dos pesquisadores. Há sempre o amparo das ciências, o eco de uma comunidade de pesquisadores. 
Num certo estado das ciências e das técnicas, nem tudo se pode fazer, medir. Não basta querer uma medida, é preciso poder tê-la; dito de outra forma, não se vê o que se quer, mas o que se pode ver. Assim, como construções significadas, os números situam-se no plano da semântica (são informações, já na origem), além de estarem, por definição, no plano da sintática (por serem signos).

O processo de pesquisa estatística é revelado em documentos metodológicos, pelos quais é possível verificar em que medida as instituições estatísticas conseguiram trabalhar com independência tecnocientífica, tendo amparo somente nas ciências e em modernos processos metodológicos, sem influência sociopolítica. Trabalhar dessa forma é vital para a qualidade das estatísticas, tendo em vista que toda e qualquer influência sociopolítica é legítima somente na fundação do programa estatístico, quando a sociedade manifesta seus desejos por certos temas a serem representados quantitativamente em detrimento de outros. Contudo, esses documentos metodológicos são elaborados para revelar apenas a lógica da justificação, como se em todo o processo de pesquisa não houvesse incertezas, indecisões, inseguranças, o que é comum, já que pesquisadores são seres humanos. Buscar conhecer essa intimidade, a dita lógica da descoberta, é de grande valor e riqueza, ainda mais se for possível fazê-lo também em sentido histórico, indicando evoluções temporais.

Contudo, isso não é fácil. Ainda mais nos tempos recentes. No passado, ao longo do Império, da Primeira República, bem como da primeira fase do IBGE (1936-1972), em que este surge como centro do sistema estatístico (noção então dada à luz), houve o cuidado de se registrar os processos, armazenando documentação abundante e valiosa. Assim, o passado torna-se visível nessa memória documental e nos permite ver e fazer a história do Brasil pela ótica do querer e do fazer as estatísticas. Dito de outra forma, pela ótica do querer essa forma de saber, e do construí-lo, tendo em vista um exercício de poder, um poder de gestão sobre as populações no território, - em si (em seus estoques e em seus movimentos), em suas ações e resultados econômicos e em suas ordens sociais - e uma gestão de poder por quem age nos e sobre os coletivos que se querem dar a conhecer. Nos últimos tempos isso mudou acarretando, infelizmente, perda de memória documental, em parte em virtude de maior divulgação das metodologias, que aparentemente dispensam a revelação das ações e atuações humanas nos processos de pesquisa, em parte pelas modernas tecnologias aplicadas também às gestões dos processos de pesquisa, em que ficaram perdidas as exigências de formalidades administrativas. O pior é que nesse tempo recente ocorreram grandes mudanças nas instituições estatísticas brasileiras, justo quando se transpôs uma produção até então fortemente técnico-administrativa para uma dimensão tecnocientífica. Dessa forma, diante da falta de memória escrita, é urgente tomar depoimentos, de modo a preservar essa história humana das pesquisas.

O estudo desse passado explica melhor o presente. Trata-se, mais do que ter séries históricas numéricas - ainda que estas sejam vitais às análises históricas -, de obter, por assim dizer, séries de decisões que envolvem atores, redes, cadeias, saberes e práticas associados à atividade estatística. Nessa perspectiva, torna-se possível compreender os processos de definição, inclusão e exclusão das chamadas categorias de classificação estatística. É, sem dúvida, um alvissareiro horizonte de investigação, bastante fecundo para a historiografia, profundamente enredado nas relações entre Estado e sociedade. Nessa via é preciso analisar 
os processos de construção intelectual das categorias de classificação, bem como os significados relativos a suas aplicações, a partir das semânticas que lhes são atribuídas pelos diferentes grupos sociais. Para tanto, o historiador social deve partir do entendimento das metodologias aplicadas às mais diversas produções estatísticas, para pensar politicamente o que elas significavam.

O mesmo ocorre com conceitos elaborados nas instituições de estatística - emprego, desemprego, renda, inflação, pobreza, mortalidade, fecundidade, entre outros -, com os métodos de coleta e de cálculo, e assim por diante. Mas não apenas a história dos conceitos, como também a história dos seus elos com as atividades políticas e sociais do país. Por exemplo, a transformação dos planejamentos de indicativos (de mobilização psicológica), sem maior rigor, em procedimentos científicos, com métodos próprios, a exigirem outro tipo de estatística, com mais abundância e mais qualidade. Corolário dessa transformação é a relevância crescente da produção estatística no que diz respeito à apreensão da realidade como suporte de descrições de situações econômicas, de denúncia de injustiças sociais, de justificação de decisões políticas e de organização de grupos de interesses. Um processo histórico pelo qual o convencional torna-se cada vez mais real, sublimando a força do agregado numérico para a orientação da ação social. Temos aí, portanto, uma história política e social.

As técnicas e as tecnologias também dão ensejo a estudos. Não se deve perder de vista que as primeiras máquinas de cálculo, depois os primeiros computadores, surgiram nas instituições estatísticas ou a elas estiveram associadas intimamente. Métodos de pesquisa nas instituições estatísticas, em especial os métodos de campo, são bastante específicos e pouco teorizados; se o fossem mais, poderiam mudar muito os livros e textos de metodologias. Por essas e muitas outras razões, as instituições estatísticas deveriam, com mais afinco, adotar uma linha permanente de pesquisa histórica, com equipe própria capacitada. Mas essa pesquisa histórica no interior das instituições estatísticas não pode e nem deve abstrair-se das relações com a pesquisa histórica acadêmica. Uma união, lado a lado, sem posições de superioridade, sem reservas de mercado, será vantajosa para ambas as partes. Há olhares distintos e complementares. Assim, um esforço de associação nos parece fundamental, e é claro que as instituições estatísticas (aqui e alhures), já tão plenas de credibilidade e de legitimidade na geração das informações estatísticas, terão muito que avançar, conquistando credibilidade e legitimidade também no âmbito da pesquisa histórica. Não é uma tarefa simples, mas não é nada impossível.

Vimos dando um passo nesse sentido com o projeto de redação de uma História das Estatísticas Brasileiras: 1822-2002, desenvolvido no CDDI do IBGE. Em quatro anos (outubro de 2003 a outubro de 2007), quatro volumes foram elaborados: o primeiro, Estatísticas desejadas: 1822-c.1889, com prefácio de Ronaldo Vainfas, cobriu o período do Império, fazendo algumas incursões ao período anterior ; o segundo, Estatísticas legalizadas: c.1889c.1936, com prefácio de Ciro Flamarion Cardoso, cobriu a primeira República, entrando brevemente no período Vargas, quando, com a instalação do Instituto Nacional de Estatística, logo IBGE, as coisas mudariam totalmente; o terceiro, Estatísticas organizadas: c.1936-c.1972, com prefácio de Angela de Castro Gomes, cobriu um período de criação e de afirmação de um sistema estatístico, que assim ganhava existência definitiva; o quarto, 
Estatísticas formalizadas: c.1972-2002, cobriu o período em que a instituição estatística central, o IBGE, se transformou em um centro de cálculo e começou a se tornar centro de ciência. ${ }^{3}$ São quatro volumes alentados, bastante extensos, mas que, não obstante, apenas puderam mostrar a ponta de um imenso iceberg. Há, sem dúvida, um imenso trabalho a continuar, a clamar pela atenção acadêmica, e é o que se quer aprofundar daqui em diante. Além disso, é claro, para nós que não basta o mundo acadêmico abraçar essa causa; é preciso o próprio IBGE fazê-lo, au grand complet, tendo ele próprio uma equipe de pesquisa histórica, que daria mais e melhor visibilidade aos acervos documentais de que é depositário.

Como dito antes, fizemos esse trabalho em íntima associação com a sociologia das estatísticas. Na perspectiva que vimos adotando, ela mostra o espectro da pesquisa geradora das estatísticas, indo de uma demanda ex ante a uma demanda ex post, passando pela oferta - etapas de produção e de disseminação. Dito de outra forma, revela o seguinte caminho: demanda ex ante $\Rightarrow$ oferta/produção $\Rightarrow$ oferta/disseminação $\Rightarrow$ demanda ex post. ${ }^{4}$ Como apontou certa vez Paul Starr (1983), a perspectiva sociológica das estatísticas públicas analisa e distingue as duas estruturas do sistema estatístico: a organização social, que consiste na relação social e econômica entre os agentes envolvidos na análise, distribuição e utilização das informações estatísticas; a organização cognitiva, que consiste no processo de construção intelectual dos pressupostos, regras, categorias de classificação e métodos de mensuração da realidade presentes na produção estatística pelos centros de cálculo (Starr, 1983). Nesse background, a pesquisa história pertinente às instituições estatísticas deve se interessar pelas fundações sociais do processo de mensuração. Há a questão da montagem da infra-estrutura de contagem da população (inovação institucional), relacionada à criação dos meios materiais de dominação do Estado Nacional. Essa vertente pode se desdobrar no estudo das relações sociais, alianças e redes de poder estabelecidas entre as elites, aproximando-se tanto da história política quanto da história social. Há, ainda, a questão do processo decisório sobre a emergência ou o abandono de séries estatísticas (política de informação).

Nesse caminho sobreleva um conjunto temático de interesse, seja em um olhar sobre o presente (do espaço nacional, ou em comparação internacional), seja em um olhar sobre o passado, tentando trazer à luz uma história. Emergido o conjunto temático, a abordagem será livre, conforme a formação do estudioso. Se for um historiador, este poderá lhe dar, caso a caso, um enfoque de história política, de história social etc.; se for um economista historiador, poderá lhe dar um enfoque de história das instituições ${ }^{5}$, de história dos métodos, das técnicas etc. Embora esse conjunto temático possa atender aos olhares externos, outros temas poderão surgir, a depender das filiações dos estudiosos acadêmicos que se mostrem interessados. Enfim, onde quer que se empreguem sobre temas vários, as estatísticas merecem (precisam mesmo) ser estudadas, e não apenas usadas.

Façamos, então, uma extração temática a partir dos quatro volumes da História das Estatísticas Brasileiras: 1822-2002, três deles já editados, o primeiro e o segundo no início e no final de 2006, respectivamente, e o terceiro, no início de 2008. O quarto, com redação concluída no final de 2007, será editado no final deste ano ou início do próximo. Por certo, vale dizer, há muitos outros temas de pesquisas, para além daqueles que estaremos destacando.

$$
\rightarrow \rightarrow \leftrightarrow<<
$$


No período do Império, seis temas pedem novas pesquisas. Primeiro, a criação de um Arquivo Estatístico na província do Rio Grande do Sul, pelo então conde de Caxias, ao final da Revolução Farroupilha. O nome usado remete aos registros administrativos, tomados à época como fontes-chaves das informações individuais fundadoras das estatísticas. Esta idéia voltaria por ocasião da criação da Diretoria Geral de Estatística (nacional), em 1871, com a sugestão de vinculá-la ao Arquivo Público (nacional). Os vários estudos, na forma de livros, mapas (na verdade, tabelas), normas etc., existentes nos arquivos de lá (muito bons, com excelente atendimento), revelam uma forte tradição estatística que remonta ao período anterior à independência, o que denota o imperativo das estatísticas na condução das guerras em que os gaúchos se envolveram. Esse material deveria/poderia ser usado em estudos e pesquisas históricas e bem merece uma recuperação sistemática, como que formando uma biblioteca estatística estadual. Além disso, há séries numéricas potenciais, que poderiam ser extraídas desses documentos. É um trabalho minucioso, difícil, mas que vale a pena. Houve ainda um órgão semelhante na província do Rio de Janeiro, estudado parcialmente.

Outro tema é a revolta contra o Censo de $1852^{6}$ e contra o registro civil que então se queria laicizar. No capítulo dedicado ao Censo não demos a devida atenção ao seu caráter 'invasor' das casas e das intimidades das pessoas; centrou-se atenção no registro civil, atribuindo-se a revolta a uma reação contra ele, mas isso precisa ser retomado. Sobre a revolta em si e suas razões políticas, ainda há muito que estudar, revelando melhor as contendas entre as partes rivais. E sobre a ausência de liderança, embora talvez seja fato, seria preciso dedicar atenção aos registros policiais das prisões havidas à época, que foram muitas, talvez vindo a surgir daí alguma figura forte ou algum tipo social mais claro. Esses registros policiais, agora no Arquivo Público Estadual, estão em precárias condições e demandam muita paciência nas buscas. Além disso, no final de 2007 a Biblioteca Nacional tornou disponíveis 58 documentos da Coleção Figueira de Mello, então chefe de polícia em Pernambuco, que não cheguei a manusear mas que são valiosos, pois ele foi figura de realce na reação à revolta (e também por sua ulterior trajetória de homem público). Outro ponto é a possibilidade de que possam existir questionários preenchidos do Censo em arquivos públicos das províncias não sublevadas. O Censo seria apurado nas províncias, vindo para a Corte apenas suas sínteses; ora, como ele foi aplicado em várias províncias antes de ser suspenso, é possível que algum material tenha se salvado no tempo.

Terceiro, os censos da Corte, uma vez que estejam nos arquivos, poderão nos levar aos mapas (tabelas) das freguesias e até aos croquis da cidade. A esse respeito, o de Haddock Lobo é especialmente interessante. Aos censos do período do Império soma-se o Censo de 1906 - ao tempo de Pereira Passos, com Aureliano Portugal e Bulhões Carvalho em seu comando -, que pode oferecer resultados interessantes, em especial ao revelar os métodos adotados no trabalho de campo. O Censo de 1920, em sua aplicação na capital, sob o olhar atento de Bulhões Carvalho, então chefe da Diretoria Geral de Estatística, poderia entrar no estudo, ajudando a entender melhor os processos censitários, bem como ampliando o alcance das séries numéricas. O IBGE possui todos esses censos da primeira República, além de alguns dos relatórios de prestação de contas. Quanto aos do Império, alguns estão como anexos aos relatórios dos ministros do Império ou da Justiça e são de fácil manuseio; já a localização de outros demandará busca em arquivos, e alguma sorte. 
Quarto tema: ao tempo do Império, à falta das estatísticas, era comum atribuir-se (por contrato específico) a terceiros a elaboração delas (estaduais). O produto final era uma corografia, misto de narrativa histórica e geográfica, pontilhada de dados estatísticos. Em geral, no início desses volumes há uma descrição dos contratos e das dificuldades encontradas, que são, no mínimo, muito curiosos, afora ajudarem a compreender os mecanismos de contratação intelectual àquele tempo. A situação de Figueira de Mello, contratado em Pernambuco, é exemplar (como consta do volume 1), mas haverá muitos outros à espera de revelações, em Minas Gerais e em São Paulo principalmente. É preciso fazer uma busca nos arquivos públicos e em bibliotecas de modo a se poder fazer estudos comparativos entre províncias ao longo do tempo. Uma pista são as fontes usadas por Joaquim Norberto no seu famoso estudo sobre o estoque da população, desde os tempos coloniais. Trata-se de Investigação sobre os recenseamentos da população geral do Império e de cada província de per se tentados desde os tempos coloniais até hoje, de 1870, com 167 páginas. Esse texto foi feito por ordem do ministro do Império, Paulino José de Sousa Soares (no gabinete Itaboraí), que também tomaria a iniciativa da lei do Censo de 1872 (o primeiro do país), enviaria Francisco de Varnhagen, o grande historiador brasileiro, como representante ao Congresso Internacional de Estatística em São Petersburgo, bem como mandaria fazer o Censo de 1870 na corte, sob o comando de Figueira de Mello.

Quinto tema: a redivisão do território. Investigamos uma tentativa de divisão de Minas Gerais que possuía clara motivação política: a de enfraquecer a bancada mineira, então a mais poderosa (as fontes são os Anais da Assembléia Geral, de fácil acesso). Há menções a outras propostas desde a Independência, mas infelizmente muitas se perderam. Um estudo que trouxesse a questão para a República, seja a primeira, sejam as seguintes, seria valioso. Houve mesmo

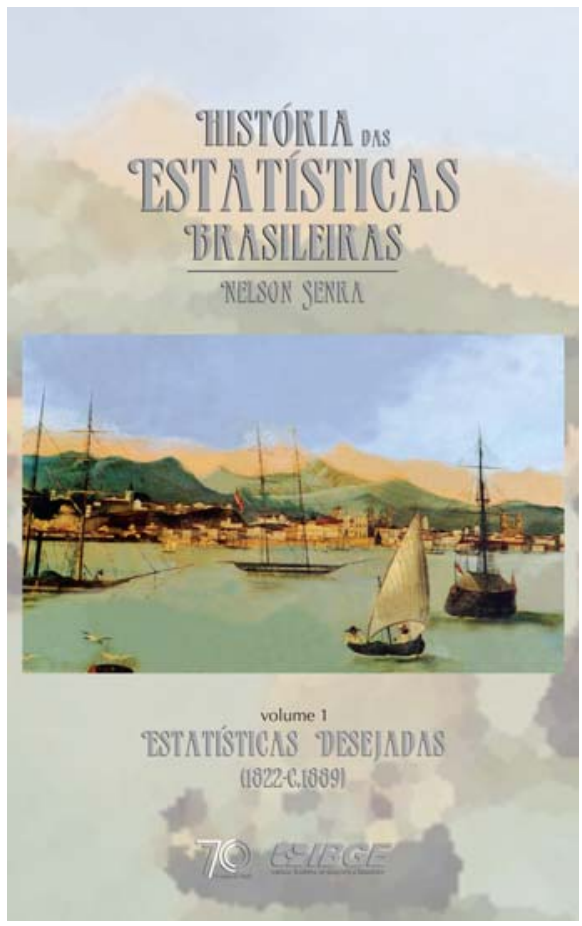
uma proposta concreta de redivisão feita por Teixeira de Freitas, fundador do IBGE, em textos publicados na Revista Brasileira de Estatística (Juarez Távora foi um de seus interlocutores nessa empreitada). Esse estudo não poderia esquecer as mudanças que afinal foram feitas, como a ulterior criação dos territórios federais, a divisão dos estados de Mato Grosso e de Goiás, bem como as atuais propostas de divisão de vários estados, que tramitam no Congresso Nacional.

Sexto e último tema, a figura de Sebastião Ferreira Soares, que merece mais atenção do que o capítulo que lhe dedicamos no volume 1. Além de ter sido um precursor da estatística brasileira (no sentido daquele tempo), foi um produtor de corografias nacionais; en passant, ele atuou no Arquivo Estatístico do Rio Grande do Sul, visto acima. Há cópias de várias de suas obras no acervo do IBGE, uma delas tendo saído pelo IPEA em edição fac-similar. ${ }^{7}$ Sua vida daria ensejo a um 
estudo sobre a participação de 'tecnocratas' no Império. Muito respeitado, sobremodo pelos ministros da Fazenda, nunca alçaria os mais altos escalões da estatística nacional, ficando restrito à área do Ministério da Fazenda. É dele a mais completa série estatística do comércio exterior do Brasil, àquele tempo.

Por fim, um trabalho grandioso, que precisaria ser assumido por alguma instituição estatística seria a formação das séries estatísticas do séc. XIX, usando-se os relatórios dos ministros às aberturas das Assembléias Gerais, além dos relatórios dos presidentes de províncias dirigidos às Assembléias Provinciais. Todos estão disponíveis no site da Universidade de Chicago (http://brazil.crl.edu/bsd/bsd/hartness/index.html). Seria um trabalho lento, difícil mesmo, a exigir equipe de trabalho.

\section{$\rightarrow \rightarrow \leftrightarrow<\leftrightarrow$}

Com respeito ao período da Primeira República, cinco temas pedem novas pesquisas. Primeiro, os sanitaristas como fundadores da demografia brasileira. As estatísticas do estoque (via Censos) e do movimento da população (via registro civil) eram essenciais à erradicação das endemias e epidemias que grassavam nas grandes cidades, em especial na capital federal, e em todo o país. Inspirados na demografia de Maurice Block ${ }^{8}$, foram críticos tenazes da qualidade das estatísticas então produzidas na Diretoria Geral de Estatística. Vale notar que essas estatísticas para fins sanitários e urbanísticos eram das poucas efetivamente demandadas pelos governos, ainda pouco afeitos à idéia de governar por números (até pelo difícil convívio com uma excessiva descentralização federativa, à época dominante). Surgem, então, grandes nomes em instituições especializadas, como Aureliano Portugal,

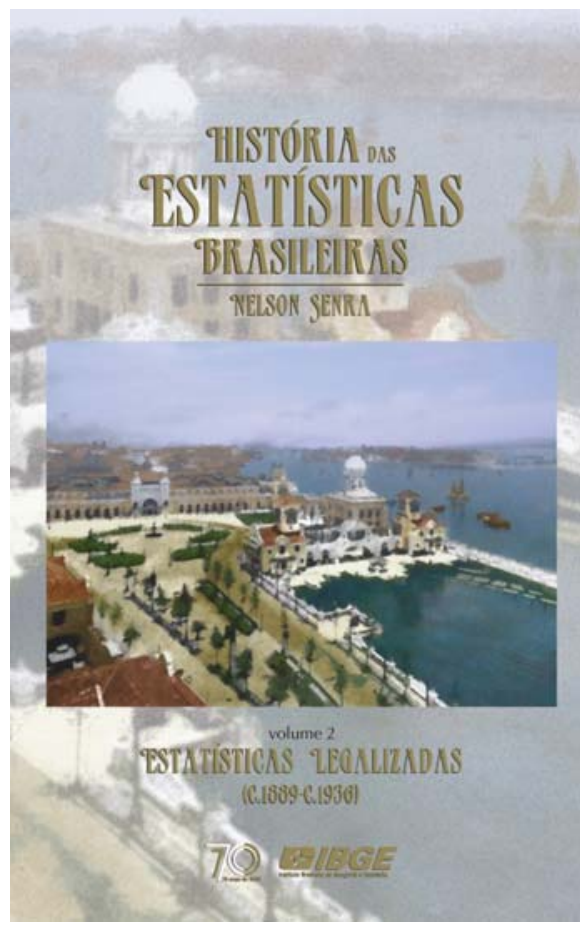
Hilário de Gouveia, Bulhões Carvalho e Oswaldo Cruz.. Esse cenário se alterará quando, em 1907, Bulhões Carvalho assumir o comando das estatísticas nacionais. Alguns textos estão disponíveis no acervo do IBGE, outros precisariam ser garimpados em outras instituições.

Segundo, a questão do registro civil. Embora o tenhamos estudado em vários capítulos do volume 2, ainda há muito por aprofundar. O registro civil é uma peça-chave na relação dos estados com as pessoas, na formação das famílias e na assunção de direitos. O Império não o fez, embora o tenha cogitado no Censo de 1852 (que não houve) e no de 1972 (o primeiro do país e único do Império). A República o implantou, atribuindo à Diretoria Geral de Estatística muito mais que a tarefa natural de derivar dele as estatísticas do movimento da população (o que é uma atribuição tradicional, mundo afora); couberam-lhe também as atribuições de controle, de revisões, além de 
outras tarefas típicas dos órgãos da Justiça. Por conta disso, há muitas fontes disponíveis no acervo do IBGE (como herdeiro do acervo da antiga Diretoria Geral de Estatística, ou do acervo doado pelos herdeiros de Bulhões Carvalho), e talvez também no Arquivo Nacional, em alusão ao Ministério da Justiça. Há pareceres de juristas, a pedido da Diretoria Geral de Estatística, e há pesquisas de campo de iniciativa de Bulhões Carvalho. Enfim, é um tema aberto a inúmeras abordagens.

Terceiro, a possibilidade de releitura do volume 2 , estudando a construção de uma instituição, no caso a Diretoria Geral de Estatística, em meio ao federalismo exacerbado que dificultava e mesmo obstruía as ações federais. Foram várias as tentativas de promover acordos com os estados (províncias), para envolvê-los num esforço harmonioso e sistemático de produção das estatísticas nacionais. Além dos acordos tentados, houve um emaranhado legislativo que, não raro, caiu no vazio, bem como a idéia de pactuar um modus vivendi e um modus operandi, por meio de um debate livre no âmbito de uma conferência de estatística (convocada para setembro de 1930, mas, por razão óbvia, não realizada). O difícil acesso aos registros administrativos (mesmo ao registro civil, em que pese o papel especial atribuído à estatística) levava a uma "deficiência de informações", como falou Bulhões Carvalho, ou seja, levava à carência de informações individuais, que são fundadoras das estatísticas.

Quarto, a renovação tecnológica, e também técnica, que foi uma marca daquele período, merece uma abordagem aprofundada. Máquinas eletrônicas foram introduzidas na apuração do Censo de 1920 (e nas pesquisas correntes), reduzindo bastante os prazos de sistematização dos dados e, assim, abreviando a divulgação dos resultados (com maior qualidade). Nessa divulgação foram usados gráficos pictóricos, muito aos moldes dos já usados no exterior. Esse tipo de gráfico, em grandes painéis, foi usado também no Pavilhão de Estatística na Exposição Comemorativa do Centenário da Independência. Tanto as máquinas quanto as técnicas de elaborar gráficos estavam em avanço no mundo, e sobre ambas há vários debates teóricos interessantes. ${ }^{9}$ Há dois capítulos no volume 2 , em abordagens que bem merecem aprofundamentos, cujas bibliografias preliminares podem/devem ser retomadas. Esses temas dariam ensejo a estudos históricos da utilização tecnológica nas instituições públicas, podendo-se somar-lhes a histórica da polêmica aquisição do primeiro computador brasileiro feita pelo IBGE, para o Censo de 1960, tal como sua posterior evolução.

Quinto: embora Bulhões Carvalho - médico, sanitarista, demografista - pontifique soberano em todo o volume 2, sua figura ainda clama por estudos biográficos (por certo analíticos). Em novembro de 2007, o IBGE comemorou o centenário de sua ascensão ao comando da estatística brasileira (1907-2007), e o fez em conjunto com a Casa de Oswaldo Cruz, da Fiocruz (leia-se Rachel Froes e Gilberto Hochman) e com a Academia Nacional de Medicina. Na ocasião, editou-se a publicação Bulhões Carvalho, um médico cuidando da estatística brasileir $a^{10}$, com vários de seus textos, bem assim textos sobre ele. Tudo isso ajuda como fonte a futuros estudos biográficos (ou monográficos, até mesmo dissertações e teses) desse notável homem público. Note-se que é de sua ação que virá o IBGE, pelas mãos de seu discípulo Teixeira de Freitas (essa associação também demanda aprofundamento).

\section{$\rightarrow \rightarrow \rightarrow<<$}


No período seguinte, que vai da criação do IBGE (formalmente instalado em 29 de maio de 1936) até a mudança de seu estatuto jurídico instituindo-o como fundação, ainda há muito que pesquisar. Um estudo do pensamento (ensinamentos) dos especialistas que moldaram aquele tempo (Giorgio Mortara, Herbert Arkin, Raymond Calton, G. Udny Yule, M.G. Kendall, Willian Madow e outros), feito em evolução com os que moldaram os tempos anteriores seria riquíssimo (no Império, Moreau de Jonnés, Adolphe Quetelet, Ernst Engel, Forjaz Sampaio e outros; na Primeira República, Maurice Block, Camille Jacquart, Filippo Virgilii e outros), sem falar nos próprios brasileiros (entre os quais Bulhões Carvalho, Lauro Sodré, Milton Rodrigues e outros). Outro estudo de trajetória seria a associação das campanhas geográficas que partiram do IBGE (talvez também das campanhas estatísticas, ainda que muito diferentes e peculiares) com as narrativas dos viajantes dos séculos XVIII e XIX; aos desenhos daquelas viagens se poderiam confrontar as fotografias (em grande quantidade) das campanhas geográficas (sem esquecer os desenhos de Percy Lau e Barbosa Leite). Aliás, a própria geografia, presente no IBGE ao lado da estatística, bem merece abordagem independente. Ainda outro estudo, dessa vez em perspectiva comparada com o tempo presente, seria a questão dos planos nacionais. Num primeiro momento, os planos eram antes de tudo de mobilização psicológica, indicativos das intenções; só depois, já a partir do regime militar, é que se tornam planos, por assim dizer, científicos, lançando mão de técnicas especiais. Em ambos os tempos o IBGE atuou, e foi a passagem de um tipo a outro de planejamento que levou a mudança do estatuto jurídico do IBGE, transformado em fundação; no primeiro caso valerá atentar para Problemas de base do Brasil, elaborado por Teixeira de Freitas ${ }^{11}$ e tido como o "Ideário cívico do IBGE" (há um capítulo sobre esse assunto no volume 3).

Há outros temas, como a concepção do IBGE como uma instituição sui generis, amparada na cooperação interadministrativa, princípio jurídico consagrado na Constituição de 1937. O Instituto nasceu sendo uma 'federação de repartições' ou 'consórcio federativo', embora tenha se valido, e muito, da força centralista do Estado Novo. Desde o início teve o direito (privilégio) de elaborar sua própria legislação (ainda que, vez ou outra, tenha precisado de legislação parlamentar). A começar da Convenção Nacional de Estatística (tida como sua 'carga magna' ou sua 'pedra angular'), pois essa legislação, no sentido de decisão formal, com força de lei, monta a quase duas mil resoluções, que ainda precisam ser estudadas de modo sistemático (no volume 3 só o fizemos parcialmente). Ao moldar suas agências municipais de estatística, o IBGE se tornou uma das raras instituições brasileiras a ter presença física em todo o território nacional. A propósito, disso

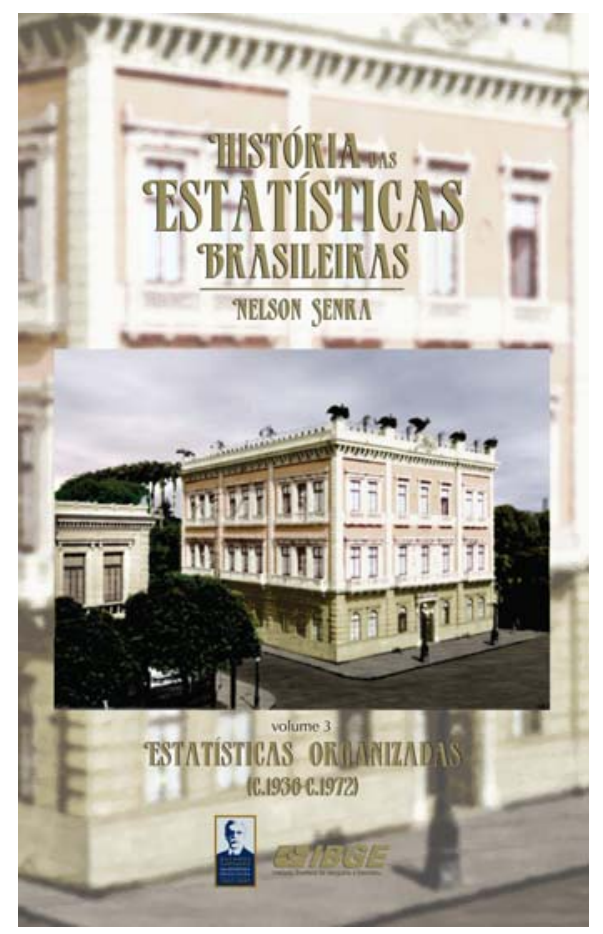


emerge a questão do municipalismo, que remonta ao período colonial e da qual o IBGE foi um prócer em seu primeiro período. Criou e editou por vinte anos a Revista Brasileira dos Municípios (1948-1968, em 84 números), cujo conteúdo - que revela redes sociais não apenas dos autores dos artigos nela publicados, perfis de grandes nomes, como também traça concepções municipalistas - foi muito pouco explorado, sendo quase inédito ${ }^{12}$; nessa questão emerge a figura de Rafael Xavier, quase ignorada atualmente, o que é uma grande injustiça histórica.

Há o tema das estatísticas educacionais com Teixeira de Freitas ${ }^{13}$, que foram, de certa forma, o pano de fundo da criação do IBGE (sem esquecer a década mineira daquele que foi o idealizador e, por muito tempo, o animador do Instituto). Nessa seara, Teixeira de Freitas atuou para além da questão de elaboração das estatísticas, sendo um debatedor influente na área, que manteve diálogos com Fernando de Azevedo, Lourenço Filho, Anísio Teixeira, Gustavo Capanema e outros, tendo presidido a prestigiosa Associação Brasileira de Educação (e na presidência da Sociedade Brasileira de Estatística, atuou o tempo todo para a formação de uma comunidade de estatistas/estatísticos/estatígrafos). Há um semnúmero de textos de sua autoria sobre o assunto, a exigir leitura profunda. Nesse e noutros pontos, diga-se, en passant, a figura de Teixeira de Freitas precisa ser recuperada, pois sua influência não se restringiu à criação e existência, ainda hoje, do IBGE; ele foi um pensador do Brasil e, segundo Angela de Castro Gomes no prefácio ao volume 3, "o protótipo do que Vargas chamava e desejava que fossem os técnicos do Brasil pós-30", tendo atuado em diferentes dimensões nacionais. Ele foi, ademais, um militante do esperanto e incentivador da adoção desse idioma como língua auxiliar da estatística brasileira. ${ }^{14}$

Além de Rafael Xavier e de Teixeira de Freitas, há a figura de Macedo Soares a merecer novos estudos, sobremodo em sua atuação na formação do campo geográfico no Brasil (o volume 4 dedica capítulo a essa temática). Há também Giorgio Mortara, que reformou a demografia brasileira depois dos demógrafos sanitaristas e que foi seguido por Lyra Madeira. Um estudo das trajetórias desses demógrafos seria valioso.

Além da já citada Revista Brasileira dos Municípios (a que se deve acrescentar a Enciclopédia dos Municípios Brasileiros), das resoluções legislativas da atividade estatística, há no acervo do IBGE um sem-número de outras fontes ainda pouco exploradas, como a Revista Brasileira de Estatística e a Revista Brasileira de Geografia, os Anuários estatísticos, entre outras. Há também cópias de ofícios e telegramas expedidos no cotidiano institucional para as autoridades da República, para o mundo externo, e mesmo para o pessoal do quadro, em todo o território nacional. E há diversos livros de atas (das Assembléias Gerais dos Conselhos Nacional de Estatística e de Geografia; das Comissões Censitárias e outros órgãos colegiados), de relatórios (de diversos eventos) e textos afins. Há também a introdução do Censo de 1940, o famoso "A cultura brasileira" de Fernando de Azevedo ${ }^{15}$, a pedir novos estudos, como as razões que pesaram na escolha de seu nome. Uma comparação com a introdução ao Censo de 1920, elaborada por Oliveira Viana, foi feita em capítulo do terceiro volume ${ }^{16}$, mas ainda há outros pontos a serem abordados, numa retomada de investigação.

O estudo das revistas brasileiras de estatística e de geografia é outro tema promissor, integrando a historiografia da imprensa periódica. Revela o processo de formação e consolidação das sociedades científicas de ambas as áreas. Com ele, seria possível sabermos 
sobre a construção de redes de solidariedade, de objetos e temas de investigação, de regras de inclusão e exclusão, circuito editorial e conteúdos de divulgação, engajado com as políticas culturais do país. Nos anos 1940 e 1950, esses periódicos reuniram a maior parte dos principais nomes da estatística e da geografia no Brasil e no mundo. Divulgaram contribuições de políticos e intelectuais proeminentes como Gilberto Freyre, Roger Bastide, Fernando de Azevedo, Lourenço Filho, Delgado de Carvalho, Roquete Pinto e Alceu Amoroso Lima. Em suas páginas deu-se muito dos debates sobre a educação do país nos tempos de Capanema, com contribuições do próprio Amoroso Lima e com vários artigos de Anísio Teixeira e de Lourenço Filho.

Enfim, o acervo do IBGE, seja em referência ao seu próprio período de existência ou em relação aos períodos anteriores, é uma potência apenas parcialmente explorada. O próprio acervo de livros, para além do acervo de memória, é muito educativo da formação das comunidades especializadas em estatística e em geografia. Boa parte dele está digitalizada, mas seus usos não são dos mais fáceis e amigáveis e há muito a se fazer ainda, de modo a motivar sua utilização por estudiosos, sobremodo historiadores. Uma visita pessoal ao acervo completo poderá ser positiva (tendo presente, contudo, que ainda há muito por ser organizado, viabilizando as descobertas e facilitando os acessos).

\section{$\rightarrow \rightarrow \leftrightarrow<<$}

Chegamos ao quarto tempo (volume 4). Antes de tudo, há os estudos de trajetórias referidos a períodos anteriores que se estendem a esse tempo, e a evolução dos conceitos é um exemplo forte disso. Como visto antes, nesse tempo a lógica da justificação é dominante na documentação; a busca da lógica da descoberta fica, assim, dependente de depoimentos que focalizem as escolhas técnicas nos vários tempos políticos. Embora venham sendo tomados depoimentos das pessoas que estiveram na linha de decisão da instituição, eles são focalizados nas trajetórias de vida, e não em pontos técnicos específicos (embora eles apareçam, aqui ou ali). Falta uma equipe de pesquisa histórica no IBGE, atuando em caráter permanente, formada por historiadores que, além de fazer estudos temáticos sistemáticos, possa, por essa própria função, orientar a recuperação e a organização dos acervos existentes, bem como colaborar na elaboração dos depoimentos (história oral).

Temos agido nesse sentido, contando sempre com o apoio (por certo discreto, talvez ainda reticente) da direção. Vimos, com proposições e realizações, intentando implantar essa linha de pesquisa histórica no IBGE, que viesse se somar à missão que tem a instituição e que cumpre com crescente competência. Além de seguir sendo a principal instituição brasileira a revelar uma representação quantitativa e cartográfica do país, no que sempre faz história, ela seria também uma instituição reveladora da história do Brasil.

Um grande passo foi dado nos dois encontros intitulados A Pesquisa Histórica no IBGE, ocorridos em 2006, quando foram ouvidas sugestões de historiadores e vários outros especialistas. ${ }^{17}$ Para o $1{ }^{\circ}$ Encontro, realizado em agosto de 2006, foi elaborado um documentobase que reúne diversas frentes de pesquisa e esboça sua fundamentação. Presentes, alguns historiadores de prestígio teceram valiosas considerações, como Guilherme Pereira das Neves (Universidade Federal Fluminense - UFF), Lúcia Bastos e Lúcia Paschoal Guimarães (ambas 
da Universidade do Estado do Rio de Janeiro - Uerj). No $2^{\circ}$ Encontro, realizado em dezembro de 2006, foram convidados diversos órgãos oficiais de pesquisa que tiveram êxito na criação de linhas de estudos históricos de perfis diversos. Estiveram reunidos representantes de instituições como Casa de Rui Barbosa, Casa de Oswaldo Cruz (COC) e Museu de Astronomia (Mast). Em pauta, questões centrais como o significado dos estudos históricos para as instituições de pesquisa fora da universidade, buscando a valorização da atividade institucional fundadora (como a área de saúde, no caso da Fundação Oswaldo Cruz). Abordaram-se sua execução, forma da escolha de projetos, formação de equipes, captação de recursos, impacto na organização e na visibilidade dos acervos - por conta das demandas contínuas criadas por essa linha -, montagem de exposições temáticas, realização de parcerias acadêmicas, integração com as atividades institucionais. No mesmo encontro, as frentes de pesquisa configuradas no documento-base foram apresentadas sob formato de um diagrama temático, que permite ampliar a visibilidade dos temas de pesquisa e mapear a extensa gama de suas possíveis associações. Foram interlocuções valiosas as de Hebe Maria Mattos (UFF), Rachel Fróes (COC), Rogério Mourão e Heloisa Bertol Domingues (Mast), Keila Grinberg (Universidade Federal do Estado do Rio de Janeiro - Uni-Rio), Rachel Valença e Kaori Kodama (Casa de Rui Barbosa), Margareth Silva Pereira e Libânia Xavier (respectivamente dos Departamentos de Arquitetura e Educação da Universidade Federal do Rio de Janeiro - UFRJ).

Em 2007, por várias razões não foi possível realizar novos encontros ${ }^{18}$, mas esperamos poder recuperar essa prática em 2008, com participação da comunidade acadêmica. A atuação nesses debates ajuda a reforçar nossos discursos de convencimento à comunidade ibgeana, mostrando quão rico é, para o IBGE e para o Brasil, essa linha de pesquisa histórica permanente. Todos ganham, é certo, não apenas o IBGE, que melhor cumpre sua missão fazendo-se mais conhecido, com também a comunidade de historiadores, que pode ampliar suas temáticas de pesquisa e enriquecer e fortalecer o campo da história da ciência no Brasil. A tarefa é difícil, pois depende da criação de uma equipe, o que pressupõe a abertura de concurso público. Mas a atenção da direção do CDDI nos permite um razoável otimismo. $^{19}$

\section{NOTAS:}

* Uma versão inicial deste texto recebeu críticas e sugestões de Alexandre de Paiva Rio Camargo, mestre em história e autor, como pesquisador convidado, de três capítulos no volume 3 e de quatro capítulos no volume 4 da História das estatísticas brasileiras.

${ }^{1}$ Nessa empreitada, tivemos o concurso de Marco Aurélio Martins Santos, jornalista e mestre em estudos populacionais e pesquisas sociais, e de Alexandre de Paiva Rio Camargo, historiador e mestre em história.

${ }^{2}$ Ver Senra, 2005. Ao longo desse livro e em referências bibliográficas comentadas dialogamos, entre outros, com Starr (1983), Morgenstern (1973), Foucault (2006, entre outros), Latour (2000a, 2000b, entre outros), Porter (1986, 1995), Hacking (1995), Rose (1991), Desrosières (1993), Giddens (2001), Martin (2001), Fellegi (1996, 1998, entre outros) e Schwartzman (1997, 2004, entre outros).

${ }^{3}$ Gilberto Hochman, pesquisador da Casa de Oswaldo Cruz/Fundação Oswaldo Cruz, aceitou convite para prefaciar o volume 4 .

${ }^{4}$ Note-se que, embora seja natural uma justaposição de atores nas duas formas de demanda, isso é irrelevante para toda e qualquer análise, seja do presente ou do passado. 
5 Os economistas historiadores, entre os quais desponta Douglass North, laureado com o Nobel de economia, manifestam especial interesse pela história das instituições.

${ }^{6}$ Em 1851, no contexto das reformas do gabinete Monte Alegre, entre as quais a Lei de Terras, o Código Comercial e a extinção do comércio de escravos, decidiu-se laicizar o registro civil e efetuar um censo populacional. A população, contudo, especialmente nos estados do Nordeste, ao que parece sem liderança, pegou em armas contra essas medidas, e o governo imperial não teve outro caminho senão adiá-las. Talvez a população tenha sido instada pelos vigários, que perdiam privilégios, ou o ocorrido tenha sido fruto da ação de bandidos, sempre muito bem armados, notadamente em decorrência da Revolta Praieira. Talvez, ainda, tenha sido como que um reacender dessa revolta, recém-debelada.

${ }^{7}$ Entre outros, Notas estatísticas sobre a produção agrícola e carestia dos gêneros alimentícios no Império do Brasil, de 1860; Esboço ou primeiros traços da crise comercial da cidade do Rio de Janeiro, em 10 de setembro de 1864, de 1865; Elementos de estatística compreendendo a teoria da ciência e a sua aplicação à estatística comercial do Brasil, de 1864-1865. O primeiro deles é que foi publicado pelo IPEA, em 1977, como volume 2 da série Pensamento Econômico Brasileiro.

${ }^{8}$ Seu livro mais famoso, do qual os demógrafos sanitaristas brasileiros extraíram o chamado Modelo Block, é Traité théorique et pratique de statistique, de 1878 (2 $\left.2^{\mathrm{a}} \mathrm{ed}.\right)$.

${ }^{9}$ Entre os principais teóricos no assunto está Tufte (1997, entre outros). Uma visita à sua página será proveitosa (http://www.edwardtufte.com/tufte/).

10 Trata-se do volume 11, de 2007, da série Memória Institucional/Documentos para Disseminação, editada pelo CDDI/IBGE.

${ }^{11}$ Trata-se de pequena brochura, que chegou a ter cinco edições. A primeira é de 1945, a última, de 1958. Nele são apontados os problemas de base do Brasil, bem como os caminhos possíveis de solução. Servia como um grande norteador do programa estatístico que cabia ao IBGE estruturar e concretizar.

12 Desde 2007 realizamos um trabalho em conjunto com o Prourb - Programa de Pós-graduação em Urbanismo (à frente, Margareth da Silva Pereira), de estudo e análise dessa revista.

${ }^{13}$ Em 2008, o IBGE planeja lançar um concurso nacional para elaboração de sua biografia de Teixeira de Freitas.

${ }^{14}$ Em 2007 publicou-se A estatística brasileira e o esperanto: uma história centenária, 1907-2007 (volume 10 da série Memória Institucional/Documentos Para Disseminação).

${ }^{15}$ Esse texto recebeu, depois, publicação independente.

16 Trata-se de "O povo brasileiro e sua evolução", de Francisco José de Oliveira Viana.

${ }^{17}$ Os anais e relatórios dos referidos encontros, juntamente com o texto de fundamentação e o diagrama temático da linha de pesquisa histórica, estão disponíveis em: http://www.ibge.gov.br/pesquisas_historicas.

${ }^{18}$ Não obstante continuamos a promover essas idéias, em várias ocasiões e em intercâmbios institucionais.

19 Além desses encontros, promovemos seminários temáticos. Em 2006 houve três, em homenagem a Mário Augusto Teixeira de Freitas, idealizador do IBGE (aos cinqüenta anos de sua morte), a Fábio de Macedo Soares Guimarães, notável geógrafo (aos cem anos de seu nascimento) e a Isaac Kerstenetzky, presidente que recriou o IBGE (aos oitenta anos de seu nascimento). Em 2007 houve homenagem a Giorgio Mortara, que refundou a demografia brasileira (aos quarenta anos de sua morte), e marcou-se os setenta anos da criação do Conselho Nacional de Geografia, bem como homenageou-se a Bulhões Carvalho, no centenário de sua assunção ao comando da estatística brasileira (esse ano foi declarado o Ano Bulhões Carvalho da Estatística Brasileira). Em 2008, declarado Ano Teixeira de Freitas da Estatística Brasileira, marcando o centenário da entrada do notável homem público (idealizador do IBGE) na atividade estatística, como membro da Diretoria Geral de Estatística, houve homenagem a José Carlos de Macedo Soares (aos quarenta anos de sua morte), e planeja-se abordar a questão do municipalismo, além de realizar nova homenagem a Teixeira de Freitas (fechando o ano festivo em sua homenagem) 


\section{REFERÊNCIAS BIBLIOGRÁFICAS}

DESROSIÈRES, Alan.

La politique des grands nombres. Paris: La Découvert. 1993.

FELLEGI, Ivan. P.

Statistical services: preparing for the future. Aguascalientes: Inegi. Versão em espanhol publicada em Estadística y Economia, Chile, n.17, p. 19-49. ene. 1999. 1998.

FELLEGI, Ivan. P.

Characteristics of an effective statistical system. International Statistical Review, London, v.64, n.2, p.165-197. 1996.

FOUCAULT, Michel.

A 'governamentalidade'. In: Foucault, Michel. Ditos \& escritos: estratégia, poder-saber. v.4. Rio de Janeiro: Forense Universitária. p.281-305. 2006.

GIDDENS, Anthony.

O estado-nação e a violência. São Paulo: Edusp. 2001.

HACKING, Ian.

The taming of chance. Cambridge: Cambridge University Press. 1995.

LATOUR, Bruno.

Ciência em ação. São Paulo: Ed. Unesp. 2000a.

LATOUR, Bruno.

Redes que a razão desconhece: laboratórios, bibliotecas, coleções. In: Baratin, Marc; Jacob, Christian (Dir). O poder das bibliotecas. Rio de Janeiro: Ed. UFRJ. p.21-44. 2000b.

MARTIN, Olivier

Da estatística política à sociologia estatística: desenvolvimento e transformações da análise estatística da sociedade (séculos XVII-XIX). Revista Brasileira de História, São Paulo, v.21, n.41, p.13-34. 2001.

MORGENSTERN, Oskar.

On the accuracy of economic observations.

Princenton: Princenton University Press. 1973.

PORTER, Theodore M.

Trust in numbers: the pursuit of objectivity in science and public life. Princenton: Princenton University Press. 1995.
PORTER, Theodore M.

The rise of statistical thinking, 1820-1900.

Princenton: Princenton University Press. 1986.

ROSE, Nikolas.

Governing by numbers: figures out democracy. Accounting, Organizations and Society, London, v.16, n.6, p.673-692. 1991.

\section{SCHWARTZMAN, Simon.}

As causas da pobreza. Rio de Janeiro: Ed. FGV. 2004.

SCHWARTZMAN, Simon.

Legitimidade, controvérsias e traduções em estatísticas públicas. Teoria \& Sociedade, Belo Horizonte, n.1, p.9-38. 1997.

SENRA, Nelson.

Estatísticas organizadas: c.1936-c.1972. Prefácio Angela de Castro Gomes Rio de Janeiro: IBGE. (História das Estatísticas Brasileiras: 1822-2002, 3). 2008.

\section{SENRA, Nelson.}

Estatísticas desejadas: 1822-c.1889. Prefácio

Ronaldo Vainfas. Rio de Janeiro: IBGE.

(História das Estatísticas Brasileiras: 1822-2002, 1). $2006 \mathrm{a}$.

SENRA, Nelson.

Estatísticas legalizadas: c.1889-c.1936. Prefácio Ciro Flamarion Cardoso Rio de Janeiro: IBGE. (História das Estatísticas Brasileiras: 1822-2002, 2). $2006 \mathrm{~b}$.

SENRA, Nelson.

O saber e o poder das estatísticas. Rio de Janeiro: IBGE. Com bibliografia comentada. 2005.

SENRA, Nelson.

Estatísticas formalizadas: c.1972-2002. Rio de Janeiro: IBGE. (História das Estatísticas Brasileiras: 1822-2002, 3). No prelo.

STARR, Paul.

The sociology of official statistics. In: William, Alonso; Starr, Paul. The politics of numbers. New York: Russel Sage Foundation. p.7-57. 1983.

TUFTE, Edward. R.

Visual and statistical thinking: displays of evidence for making decisions. Connecticut: Graphic Press. 1997. 